\title{
CONGRESO SOBRE AVENIDAS FLUVIALES E INUNDACIONES EN LA CUENCA DEL MEDITERRÁNEO, MURCIA-ALICANTE, 11-14 DE MAYO DE 1988
}

Por

FRANCISCO FRANCO SÁNCHEZ

Entre los días 11 y 14 de mayo de 1988 y en las ciudades de Murcia y Alicante se celebró la reunión científica internacional sobre Avenidas fluviales e inundaciones en la cuenca del Mediterráneo, bajo los auspicios del European Centre for Research and Documentation in Social Sciences del Centro de Viena (cuyo representante de España es Míkel de Epalza), con el patrocinio de la C.A.M., de la Secretaría del Estado de Universidades e Investigación y la Conserjería de Política Territorial y Obras Públicas de la Comunidad Autónoma de Murcia, y bajo la organización del Instituto de Geografía de la Universidad de Alicante. El coloquio quedaba encuadrado en el marco de la aportación del Instituto de Geografia de la Universidad de Alicante al Proyecto Internacional L'eau et les hommes dans les pays de la Méditerranée et la mer Noire. Las diferentes aportaciones se articularon en torno a seis ponencias: «Causas climáticas de las riadas», "Ríos y ramblas mediterráneos», "Llanos de inundación», «Grandes avenidas e inundaciones históricas», "Prevención y control de avenidas" y «Leyes y otras normas en torno a crecidas fluviales".

Dejando aparte los interesantísimos debates geográficos y dentro de nuestro marco de interés histórico, hemos de reseñar la cuarta ponencia, la centrada en las «Grandes avenidas e inundaciones históricas", en cuyas comunicaciones se analizó su diferente incidencia a lo largo del tiempo. Entre las comunicaciones englobadas dentro de esta ponencia hay que citar, por tratar de tema árabe, la de Robert Pocklington "Observaciones sobre el aprovechamiento del agua torrencial para la agricultura en Murcia y Lorca durante la época árabe» centrada en las noticias de las fuentes árabes, que hablan de un sistema de laminar avenidas por medio de las acequias, usado por los musulmanes murcianos y lorquinos; éstos aprovechaban y redistribuían así el limo arrastrado en las avenidas, el cual se depositaba en las tierras de labor, 
produciendo como resultado una gran fertilidad. El estudio de Abdel Hakim EI Gafsi sobre «Crues, inondations et contrôle de l'eau dans quelques villages moriscos andalous de Tunisie», en que se describen los métodos usados por los moriscos expulsados de la Península lbérica en el valle del río Medjerda, en Túnez, para el control del agua, tanto de uso corriente, como de avenidas. Finalmente hay que reseñar e! estudio de Francisco Franco Sánchez "Noticias de época islámica sobre inundaciones fluviales en el Baix Vinalopó y en la Vega Baja del Segura», en el que se analizarı dos hechos transmitidos por las fuentes árabes y la presencia de una torre-atalaya en la muralla de Orihuela que remiten a crecidas de los ríos Segura y Vinalopó en el período islámico.

Las Actas de la Reunión ya han sido publicadas: Avenidas fluviales e inundaciones en la cuenca del Mediterráneo, Murcia, ed. Instituto Universitario de Geografía de la Universidad de Alicante/C.A.M., 1989, estando los artículos mencionados en las pp. 375-394, 395-401 y 403-413. 